\title{
HYSTEROSALPINOGRAPHY VERSUS DIAGNOSTIC LAPAROSCOPY IN ASSESSMENT OF TUBAL PATENCY
}

\author{
By \\ Mostafa H. Hegab, Ahmed S. Mohammed and Ahmed M. Khalil \\ Department of Obstetrics and Gynecology, Faculty of Medicine, Al-Azhar University
}

Corresponding author: Ahmed M. Hafez Khalil, E-mail: alwforever@gmail.com

Mobile: 01068975353

\begin{abstract}
Background: Investigations of tubal factor of infertility include hystero-salpingography, saline infusion sonohysterography as well as diagnostic laparoscopy with chromotubation. Hysterosalpingography (HSG) is a contrast study of the uterine cavity and fallopian tubes.

Objective: To compare the role of laparoscopy and hysterosalpingograpy in the assessment of tubal factor of infertility.

Patients and Method: This study was carried out on eighty patients attending the gynecology outpatient clinic of Al-Hussein Hospital, Al-Azhar University. It included forty patients with primary infertility and forty patients with secondary infertility, all with minimum duration of one year after taking a written consent. complete laboratory investigation was done including CBC, PT, PTT, INR, HBV, HCV, HIV, Cr, Urea, ALT, AST. This study started at Oct 2017 and finished at Aug 2019.

Results: Results of comparison of tubal patency assessment during Laparoscopy and its compatibility with previous hysterosalpingography results in case of female infertility were: In 55 cases that were diagnosed as free from tubal block by diagnostic laparoscopy $\{\mathrm{DL}\}$, only 40 cases were confirmed by HSG (73.2\%), while the other 11 cases were diagnosed as (2 cases bilateral block (4.9\%), 4 cases Lt. block (9.8\%), 3 cases minimal spill $(7.3 \%)$ and 2 cases as Rt. Block (4.9\%). In the 9 cases that were diagnosed as bilateral tubal block by DL, only 4 were confirmed by HSG (42.9\%), while the other 5 cases were diagnosed free by HSG (57.1\%). Twelve cases were diagnosed as unilateral tubal block by DL, 3 cases were confirmed by HSG, while 7 cases were diagnosed as free and one case was diagnosed as bilateral block by HSG. Peritubal adhesions were seen in $18.3 \%$ in all cases, of which $18.8 \%$ had Rt block, $27.3 \%$ had Lt block, and $54.5 \%$ had bilateral tubal patency. In 11 cases diagnosed as unilateral peritubal adhesion by DL, only 2 cases (Rt \& Lt) were confirmed by HSG (39.3\%). Fifty three cases were diagnosed as the Rt tube was free of adhesion by DL, 4 cases HSG were diagnosed as Rt peritubal adhesion (7.5\%), while 56 cases were diagnosed as Lt tube free of adhesion by DL and 5 cases HSG were diagnosed as Lt peritubal adhesion (8.9\%).
\end{abstract}

Conclusion: Diagnostic laparoscopy has more accuracy in assessment of tubal patency in infertile patients more than hysterosalpingogram.

Key words: Hysterosalpinography diagnostic laparoscopy, tubal patency

\section{INTRODUCTION}

Approximately, $15 \%$ of married couples are infertile, and in $32 \%$ of these couples the dysfunction is associated with the female partner. The most common female abnormalities are related to fallopian tube patency (40\%), or ovulation (40\%) (Nandi and Homburg, 2016). Tubal occlusive disease is an important cause of infertility and should be specifically 
excluded (American Society for reproductive medicine, 2014).

Hysterosalpingography (HSG) and diagnostic laparoscopy (DL) are important diagnostic tools in gynecological practice. These are the investigations of choice when uterine pathology, tubal factor or peritoneal adhesions are suspected to be the cause of infertility. In such patients the diagnostic workup should start with HSG which is a very useful initial screening test. Laparoscopy is inspection of the pelvic cavity through a cold light endoscope, passed through the abdominal wall under anesthesia. During this procedure a dye can be injected through a cannula in uterine cervix to test the patency of fallopian tubes (Schankath et al., 2012). This investigation is now frequently performed, but it does carry potentially serious risks, (e.g. perforation of viscous, hemorrhage due to blood vessel damage, or a trocar punctures (Wadhwa et al., 2017). This technique only indicates patency of entire hysterosalpingeal complex but does not provide information concerning the location of the potential abnormality (Dusak et al., 2013).

Hysterosalpingography (HSG) is an invaluable procedure for evaluating internal architecture of female reproductive tract. It is significally more accurate in showing patency of fallopian tubes and predicting future prognosis in patient being managed for infertility. It is less invasive as compared to laparoscopy and is almost equally useful method for evaluating female pelvic pathologies (American Society for reproductive medicine, 2014).
The aim of this work was to compare the role of laparoscopy and hysterosalpingograpy in the assessment of tubal factor of infertility.

\section{PATIENTS AND METHODS}

This was a prospective cohort study that carried out on eighty patients attending the Gynecology outpatient clinic of Al-Hussein University Hospital. It included forty patients with primary infertility and forty patients with secondary infertility, all with at least 1 year of infertility after taking written consents. The study started at Oct 2017 and finished at Aug 2019.

The study included patients with ages between $20 \mathrm{y}$ and $35 \mathrm{y}$, history suggestive of tubal factor of infertility. History of previous appendectomy or history of puerperal sepsis, history suggestive of endometriosis (for example dyspareunia, dysmenorrhea), deep pelvic pain and history suggestive of previous pelvic inflammatory disease or sexually transmitted diseases were investigated.

Patients exposed to hysterosalpingography in the proliferative phase of the first cycle as an outpatient procedure, and then in the proliferative phase of the following cycle, patients were admitted to the inpatient department for laboratory investigation, anesthetic checkup and evaluation, and diagnostic laparoscopy with laparoscopic chromotubation.

Investigations included complete blood count, fasting and two hours blood sugar, liver and kidney function tests. Anesthetic consultation and checkup was done for proper evaluation of patients' risk factors. 


\section{HYSTEROSALPINOGRAPHY VERSUS DIAGNOSTIC LAPAROSCOPY IN...}

Patients were asked to fast over night before the day of the operation. Diagnostic laparoscopy was performed by the same machine type (KARL STORZ ENDOSCOPE) under general anesthesia, with endotracheal intubation to minimize the risk of aspiration.

\section{Statistical analysis:}

The following tests were done: Kappa measure of agreement between fibroscan and biopsy in detecting fibrosis stage. A value of: $\quad 0-0.20$ indicated slight agreement; $0.21-0.40$ fair agreement; 0.41-0.60 moderate agreement; $0.61-0.80$ substantial agreement; and 0.81-1.00 almost perfect agreement.

Recorded data were analyzed using the statistical package for social sciences, version 20.0 (SPSS Inc., Chicago, Illinois, USA). Qualitative data were expressed as frequency and percentage.

\section{RESULTS}

In the 55 cases diagnosed as free by DL. Cnly 40 cases were confirmed by HSG, 19 cases were diagnosed as tubal block by HSG, while 9 cases were diagnosed as bilateral block by DL. Only 4 cases were confirmed by HSG, 5 cases were diagnosed as free by HSG. 12 cases were diagnosed as unilateral block by DL, 3 cases were confirmed by HSG, while 7 cases were diagnosed as free and one case was diagnosed as bilateral block by HSG (Table 1).

Table (1): Hysterogram and diagnostic laparoscopy among all study cases in assessment of tubal patency

\begin{tabular}{|c|c|c|c|c|c|c|c|}
\hline \multicolumn{2}{|c|}{ HSG-Tubes } & Bil.Block & $\begin{array}{c}\text { Delayed } \\
\text { spill }\end{array}$ & Free & $\begin{array}{c}\mathbf{L t} \\
\text { block }\end{array}$ & $\begin{array}{c}\mathbf{R t} \\
\text { block }\end{array}$ & Total \\
\hline \multirow{2}{*}{ Bil. Block } & No. & 4 & 0 & 3 & 0 & 1 & 8 \\
\hline & $\%$ & $50.0 \%$ & $0.0 \%$ & $37.5 \%$ & $0.0 \%$ & $12.5 \%$ & $100.0 \%$ \\
\hline \multirow{2}{*}{ Free } & No. & 5 & 4 & 40 & 6 & 1 & 56 \\
\hline & $\%$ & $8.9 \%$ & $7.1 \%$ & $71.4 \%$ & $10.7 \%$ & $1.8 \%$ & $100.0 \%$ \\
\hline \multirow{2}{*}{ Lt. Block } & No. & 0 & 0 & 5 & 2 & 0 & 7 \\
\hline & $\%$ & $0.0 \%$ & $0.0 \%$ & $71.4 \%$ & $28.6 \%$ & $0.0 \%$ & $100.0 \%$ \\
\hline \multirow{2}{*}{$\begin{array}{c}\text { Minimal cnill } \\
\text { spin } \\
\end{array}$} & No. & 0 & 0 & 4 & 1 & 0 & 5 \\
\hline & $\%$ & $0.0 \%$ & $0.0 \%$ & $80.0 \%$ & $20.0 \%$ & $0.0 \%$ & $100.0 \%$ \\
\hline \multirow{2}{*}{ Rt. Block } & No. & 0 & 0 & 3 & 0 & 1 & 4 \\
\hline & $\%$ & $0.0 \%$ & $0.0 \%$ & $75.0 \%$ & $0.0 \%$ & $25.0 \%$ & $100.0 \%$ \\
\hline \multirow{2}{*}{ Total } & No. & 9 & 4 & 55 & 9 & 3 & 80 \\
\hline & $\%$ & $11.3 \%$ & $5.0 \%$ & $68.8 \%$ & $11.3 \%$ & $3.8 \%$ & $100.0 \%$ \\
\hline
\end{tabular}

Agreement was statistically tested which showed that Kappa equal 0.114 and it was statistically significant. ( $\mathrm{P}$ value $<0.001)$. Although agreement is statistically significant yet differences are clinically obvious.

In 11 cases diagnosed as unilateral peritubal adhesion by DL, only 2 cases (Rt \& Lt) were confirmed by HSG (39.3\%). 53 cases were diagnosed as the Rt tube free of adhesion by DL, 4 cases HSG were diagnosed as Rt peritubal adhesion (7.5\%), while 56 cases were diagnosed the Lt tube free of adhesion by DL, 5 cases HSG were diagnosed as Lt peritubal adhesion (8.9\%) (Table 2). 
MOSTAFA H. HEGAB et al.,

Table (2): Hysterosalpingogram and diagnostic laparoscopy among all study cases in assessment of Rt and Lt Peritubal adhesion

\begin{tabular}{|c|c|c|c|c|c|}
\hline \multirow{8}{*}{$\begin{array}{l}\text { HSG-Rt } \\
\text { peritubal } \\
\text { adhesion }\end{array}$} & & & \multicolumn{2}{|c|}{ DL- peritubal adhesion } & \multirow[t]{2}{*}{ Total } \\
\hline & & & No & Yes & \\
\hline & \multirow[t]{2}{*}{ No } & No. & 65 & 8 & 73 \\
\hline & & $\%$ & $89.0 \%$ & $11.0 \%$ & $100.0 \%$ \\
\hline & \multirow[t]{2}{*}{ Yes } & No. & 5 & 2 & 7 \\
\hline & & $\%$ & $71.4 \%$ & $28.6 \%$ & $100.0 \%$ \\
\hline & \multirow[t]{2}{*}{ Total } & No. & 65 & 8 & 73 \\
\hline & & $\%$ & $89.0 \%$ & $11.0 \%$ & $100.0 \%$ \\
\hline \multirow{6}{*}{$\begin{array}{l}\text { HSG-Lt } \\
\text { peritubal } \\
\text { adhesion }\end{array}$} & \multirow[t]{2}{*}{ No } & No. & 68 & 4 & 72 \\
\hline & & $\%$ & $94.4 \%$ & $5.6 \%$ & $100.0 \%$ \\
\hline & \multirow[t]{2}{*}{ Yes } & No. & 7 & 1 & 8 \\
\hline & & $\%$ & $87.5 \%$ & $12.5 \%$ & $100.0 \%$ \\
\hline & \multirow[t]{2}{*}{ Total } & No. & 75 & 5 & 80 \\
\hline & & $\%$ & $93.8 \%$ & $6.3 \%$ & $100.0 \%$ \\
\hline
\end{tabular}

Agreement was statistically tested which showed that kappa in Rt-pcritubal adhesion equal 0.108 and Lt-peritubal adhesion equal 0 . and there were statistically not significant.

In 55 cases who were diagnosed as free of other tubal finding by DL, 7 cases HSG found other tubal finding (one salpingitis, 2 hydrosalpinx, 7 peritubal post inflammatory changes). three cases were diagnosed by DL as hydrosalpinx, two case were confirmed by HSG and one was diagnosed as free by HSG (Table 3).

Table (3): Hysterosalpingogram and diagnostic laparoscopy among all study cases in assessment of other tubal finding

\begin{tabular}{|c|c|c|c|c|c|c|}
\hline \multirow{2}{*}{\multicolumn{2}{|c|}{$\begin{array}{l}\text { Other tubal finding by } \\
\text { HSG }\end{array}$}} & \multicolumn{4}{|c|}{ Other tubal finding by DL } & \multirow{3}{*}{$\begin{array}{c}\text { Total } \\
1 \\
1\end{array}$} \\
\hline & & \multirow{2}{*}{$\begin{array}{c}\begin{array}{c}\text { Congested } \\
\text { tube }\end{array} \\
0 \\
\end{array}$} & \multirow{2}{*}{$\begin{array}{c}\text { convoluted } \\
0\end{array}$} & \multirow{2}{*}{$\begin{array}{c}\text { hydrosalpinx } \\
0 \\
\end{array}$} & \multirow{2}{*}{$\begin{array}{c}\text { None } \\
1\end{array}$} & \\
\hline Salpingitis & No. & & & & & \\
\hline & $\%$ & $0.0 \%$ & $0.0 \%$ & $0.0 \%$ & $1.4 \%$ & $1.3 \%$ \\
\hline \multirow[t]{2}{*}{ Hydrosalpinx } & No. & 0 & 1 & 3 & 4 & 8 \\
\hline & $\%$ & $0.0 \%$ & $100.0 \%$ & $75.0 \%$ & $5.4 \%$ & $10.0 \%$ \\
\hline \multirow[t]{2}{*}{ None } & No. & 1 & 0 & 1 & 64 & 66 \\
\hline & $\%$ & $100.0 \%$ & $0.0 \%$ & $25.0 \%$ & $86.5 \%$ & $82.5 \%$ \\
\hline \multirow{2}{*}{$\begin{array}{c}\text { Peritubal post } \\
\text { inflammatory } \\
\text { changes }\end{array}$} & No. & 0 & 0 & 0 & 5 & 5 \\
\hline & $\%$ & $0.0 \%$ & $0.0 \%$ & $0.0 \%$ & $6.8 \%$ & $6.3 \%$ \\
\hline \multirow[t]{2}{*}{ Total } & No. & 1 & 1 & 4 & 74 & 80 \\
\hline & $\%$ & $1.3 \%$ & $1.3 \%$ & $5.0 \%$ & $92.5 \%$ & $100.0 \%$ \\
\hline
\end{tabular}


HYSTEROSALPINOGRAPHY VERSUS DIAGNOSTIC LAPAROSCOPY IN...

Table (4): Detection of uterine status by hysterosalpingogram and diagnostic laparoscopy

\begin{tabular}{|c|c|c|c|}
\hline Hysterosalpingogram & & No. & \% \\
\cline { 2 - 4 } & Normal uterine cavity & 74 & $92.5 \%$ \\
\cline { 2 - 4 } & Filling defect & 3 & $3.8 \%$ \\
\cline { 2 - 4 } & Bicornuate uterus & 1 & $1.3 \%$ \\
\cline { 2 - 4 } & Subseptat uterus & 1 & $1.3 \%$ \\
\cline { 2 - 4 } & Uterus didelphys & 1 & $1.3 \%$ \\
\hline \multirow{4}{*}{ Diapnostic } & Total & 80 & $100.0 \%$ \\
\cline { 2 - 4 } & Free & 71 & $88.8 \%$ \\
\cline { 2 - 4 } & Fibroid & 7 & $8.8 \%$ \\
\cline { 2 - 4 } & Arcuate & 1 & $1.3 \%$ \\
\cline { 2 - 4 } & Linicornuate & 1 & $1.3 \%$ \\
\cline { 2 - 4 } & Tout & 80 & $100.0 \%$ \\
\hline
\end{tabular}

\section{DISCUSSION}

Infertility is generally defined as one year of unprotected intercourse without conception. Approximately, 85-90\% of healthy young couples conceive within one year. Infertility therefore, affects 10 $15 \%$ of couples and is an important part of clinical practice of most clinician (American Society for reproductive medicine, 2014).

In our study, we found that diagnostic laparoscopy was more accurate in assessment of tubal patency rather than hysterosalpingography.

HSG is quite accurate in defining the uterine cavity. Laparoscopy, on the other hand, is not able to give information on the uterine cavity. Laparoscopy is superior to histerosalpingography in the assessment of tubal patency and allows detection and treatment of intra-abdominal pathologies as endometriosis and peritubal adhesions (Foroozanfard and Sadat, 2013).

In the 55 cases that were diagnosed as free from tubal block by DL, only 40 cases were detected by HSG $(72.7 \%)$, while the other 15 cases $(27.3 \%)$ were diagnosed as 3 cases with bilateral block, 6 cases with Lt. block, 3 cases with minimal spill, and 3 cases as Rt block.
In the nine cases that were diagnosed as bilateral tubal block by DL, only 4 cases were detected by HSG (44.4\%), while the other 5 cases were diagnosed as free by HSG (55.6\%). Twelve cases were diagnosed as unilateral block by DL, 3 cases were detected by HSG, while 7 cases were diagnosed as free and one case was diagnosed as bilateral block by HSG. Four cases were diagnosed as delayed spill by DL, while HSG diagnosed of them as free.

In our study, 11 cases were diagnosed as unilateral peritubal adhesion by DL (7 cases as Rt \& 4cases as Lt). Only 2 cases were detected by HSG (one as Rt and one as Lt). Ffty three cases were diagnosed as Rt tube free of adhesion by DL. Forty nine cases were detected by HSG $(92.5 \%)$, and 4 cases were diagnosed as Rt peritubal adhesion $(7.5 \%)$. Fifty six cases were diagnosed Lt tube free of adhesion by DL, 51 cases were detected by HSG $(91.1 \%)$ and 5 cases were diagnosed as Lt peritubal adhesion $(8.9 \%)$. Fourteen cases of intraabdominal adhesion were diagnosed by DL; only 4 cases HSG were confirmed with DL (28.6\%). while 10 cases were diagnosed as free from adhesion by HSG (71.4\%). 
Eighteen cases of intra-abdominal adhesion were diagnosed by DL, 5 cases HSG were confirmed with DL (27.8\%), while 13 cases were diagnosed by HSG as free $(72.2 \%)$.

In 62 cases were diagnosed by DL as free from intra-abdominal adhesion, 5 cases were diagnosed by HSG as intraabdominal adhesion (11.3\%).

In 55 cases who were diagnosed as free of other tubal finding by DL, 7 cases HSG found other tubal finding (one salpingitis, 2 hydrosalpinx, 7 peritubal post inflammatory changes). 3 cases were diagnosed by DL as hydrosalpinx, 2 cases were confirmed by HSG and one was diagnosed as free by HSG.

In our study, the information retrieved during DL was more informative than during HSG were: $8.3 \%$ cases had fibroids that were not encroaching on the endometrial cavity. 95\% cases had normal ovary, $1.7 \%$ cases had Ovarian cyst. $1.7 \%$ cases had Tubo-ovarian complex and $1.7 \%$ cases had picture suggestive of polycystic ovarian disease (thick cortex, peripherally arranged multiple follicles, large ovarian volume). The information retrieved during $\mathrm{HSG}$ was more informative than during DL were: $3.3 \%$ cases had filling defect and 55\% cases had normal uterine cavity. HSG in our study was the less accurate examination in uterine malformation detection. In our study one case was diagnosed as Lt tubal block by HSG, while by DL diagnosed as unicornuate uterus. Two cases were diagnosed as bicomuate uterus and uterus didelphys by HSG, while diagnosed as normal uterus by DL.

In agreement with our study results, a study by Kahyaoglu et al. (2009), hhe correlation between HSG and DL findings was identified. A total $64 \%$ patients who underwent DL for evaluating unexplained infertility had pelvic pathologies, while $36 \%$ of them were free of pelvic disease. $37 \%$ of primary infertile patients and $44 \%$ of secondary infertile patients had HSG abnormalities before DL. $60 \%$ of the primary infertility patients and $69 \%$ of the secondary infertile patients had pelvic pathologies related to infertility regardless of HSG abnormalities preoperatively.

Habibaj et al. (2011) Compared between Transvaginal sonography after diagnostic Hysteroscopy and Laparoscopic Chromopertubation for the assessment of tubal patency in infertile women. The study results were the presence of fluid in the pouch of Douglas was observed in 37 of the 56 cases. In 36 of these cases, unilateral or bilateral tubal patency was confirmed by DL. In 17 of the remaining 19 cases (without fluid in the pouch of Douglas during ultrasound), bilateral tubal occlusion was confirmed by DL.

\section{CONCLUSION}

- From the results of our study, we conclude that Diagnostic laparoscopy have more accuracy in assessment of tubal patency in infertile patients more than hysterosalpingogram.

- In the absence of tubal block, hysterosalpingography has good results as negative tests and in the presence of tubal block has false negative results.

- While diagnostic laparoscopy in the absence of tubal block and in the presence of tubal block or in the presence of pelvic disease without block, as in cases of endometriosis or 


\section{HYSTEROSALPINOGRAPHY VERSUS DIAGNOSTIC LAPAROSCOPY IN...}

peritubal adhesions has excellent results, which remains the gold standard in the investigations of tubal factor of female infertility.

\section{REFERENCES}

1. American Society for Reproductive Medicine (2014): Revised American Society for Reproductive Medicine classification of endometriosis Fertile Sterile. 67:817-822.

2. Dusak A, Soydinc HE, Onder H, Ekinci F, Görük NY, Hamidi C and Bilici A. (2013): Venous intravasation as a complication and potential pitfall during hysterosalpingography: Re-emerging study with a novel classification. Journal of Clinical Imaging Science.; 3: 67-72.

3. Foroozanfard F and Sadat Z. (2013): Diagnostic value of hysterosalpingography and laparoscopy for tubal patency in infertile women. Nursing and Midwifery Studies, 2(2):188-194.

4. Habibaj J, Kosova H, Bilali S, Valbona B and Diana $Q$ (2012): Comparison between transvaginal sonography after diagnostic hysteroscopy and laparoscopic chromopertubation for the assessment of tubal patency in infertile women. J Clin Ultrasound, 40(2):68-73.

5. Nandi A and Homburg R. (2014): Unexplained subfertility: diagnosis and management. The Obstetrician \& Gynaecologist. 18(2):107-15.

6. Practice Committee of the American Society for Reproductive Medicine (2014): Report on varicocele and infertility: a committee opinion. Fertility and Sterility, 102(6):1556-60.

7. Schankath AC, Fasching N, Urech-Ruh C, Hohl MK and Kubik-Huch RA. (2012): Hysterosalpingography in the workup of female infertility: indications, technique and diagnostic findings. Insights into imaging. 3(5):475-83

8. Wadhwa L, Rani P and Bhatia P. (2017): Comparative prospective study of Hysterosalpingography and hysteroscopy in infertile women. Journal of Human Reproductive Sciences. 10(2):73_82. 


\section{مقارنة بين الأشعة بالصبغة ومنظار البطن فى تقبيم قناة

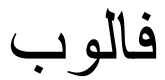

\section{مصطقى حسين حجاب، أحمد شعبان محمد، أحمد محمد حافظ خليل}

\section{قسم أمراض النساء والتوليد، كلية الطب، جامعة الأزهر}

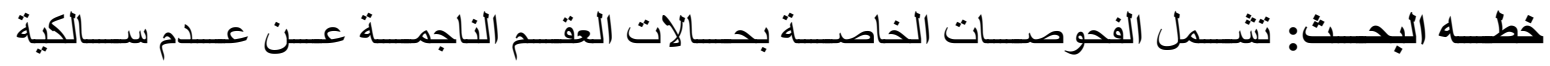

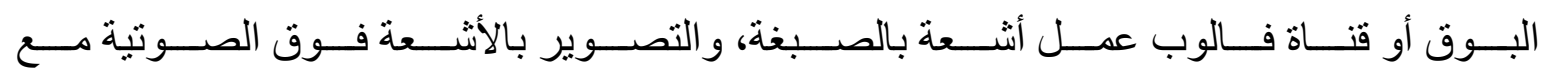

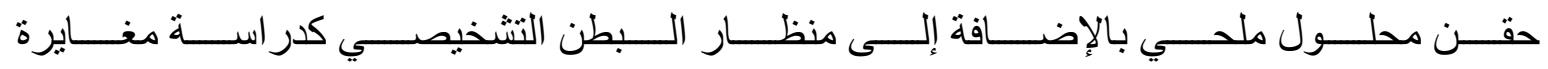
لتجويف الرحم وقناتي فالوب.

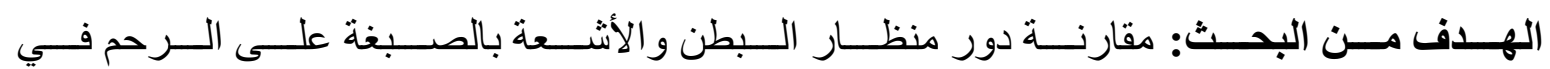
تقييم عامل البوق كأحد أسباب العقم.

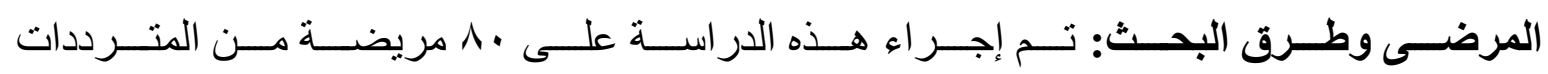

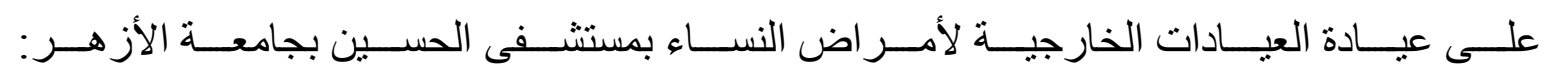

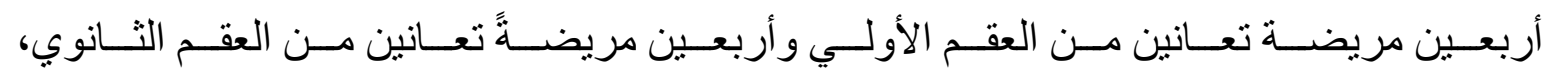

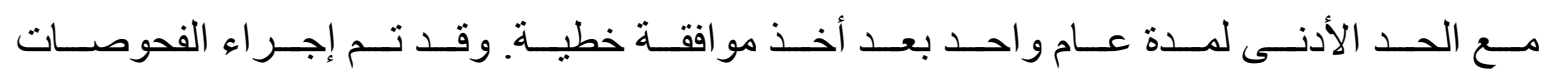

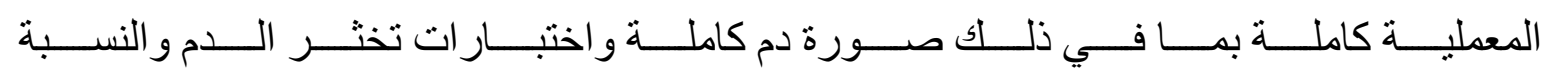

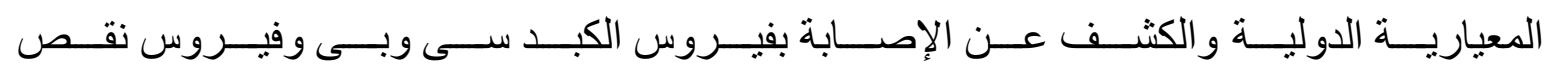

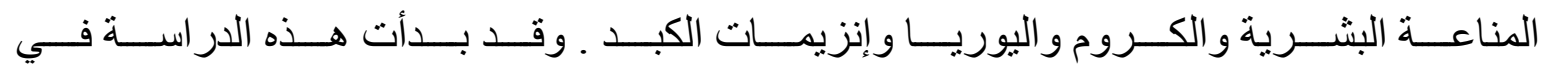

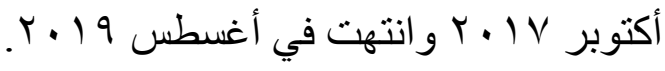

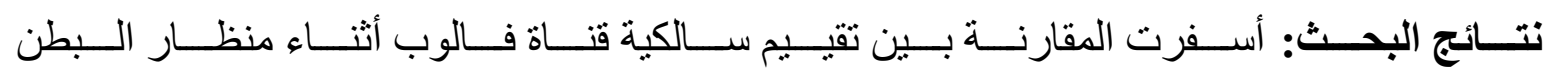

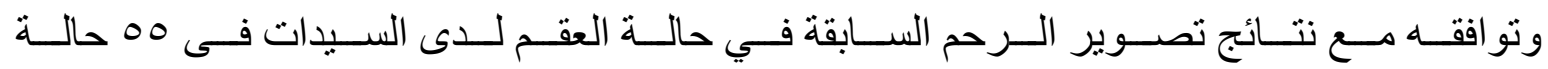

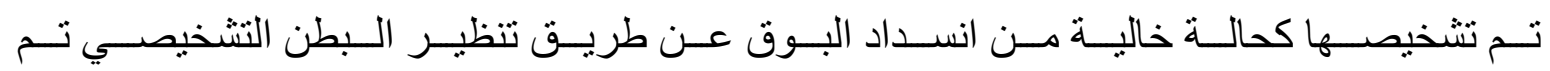

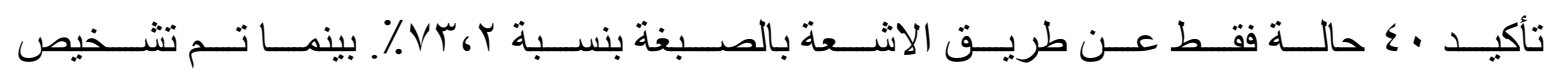

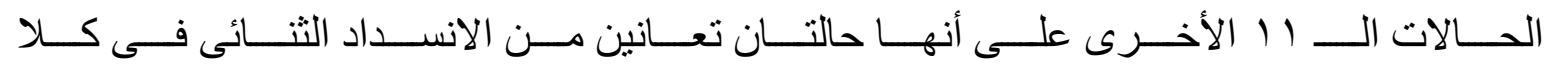

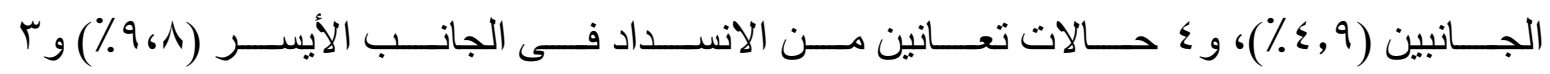

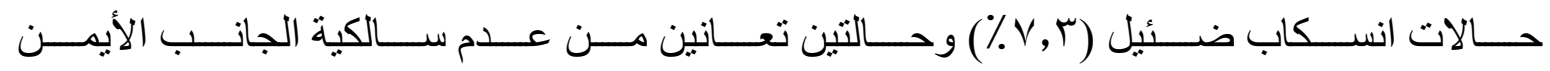

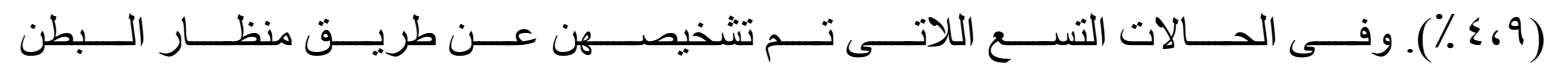




\section{HYSTEROSALPINOGRAPHY VERSUS DIAGNOSTIC LAPAROSCOPY IN... 549}

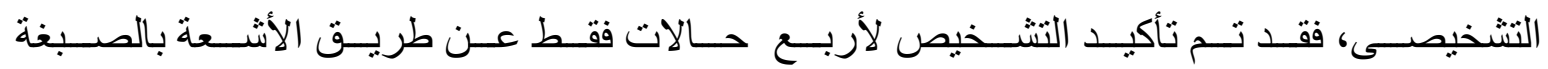

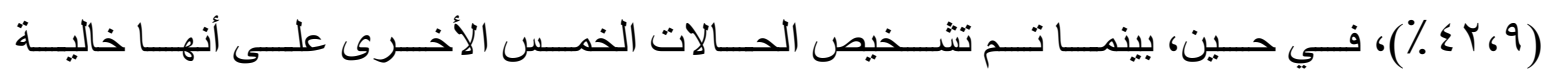

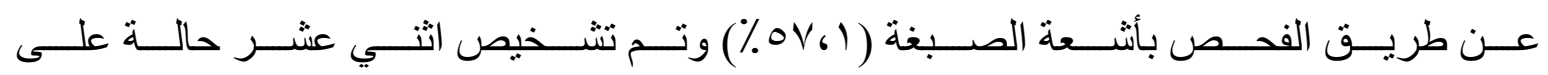

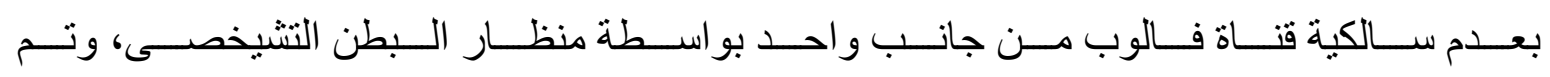

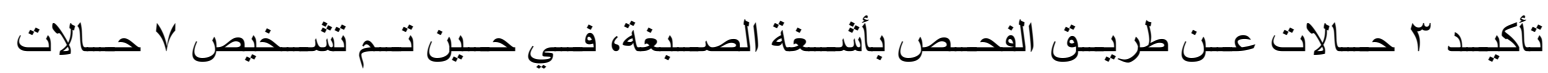

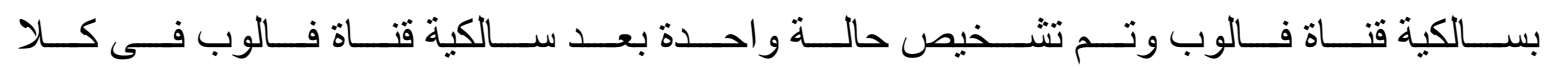

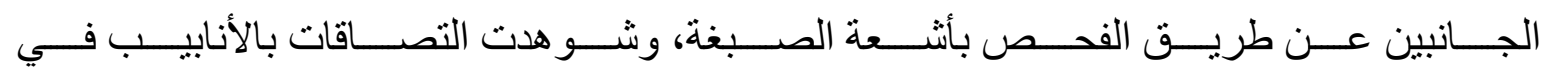

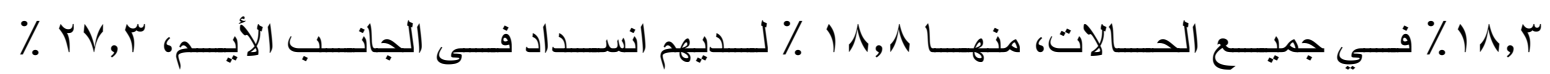

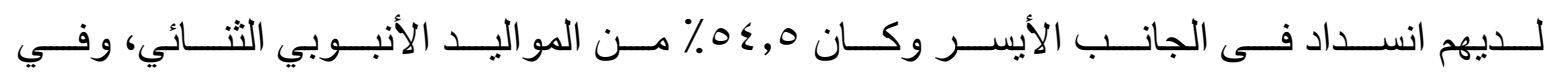

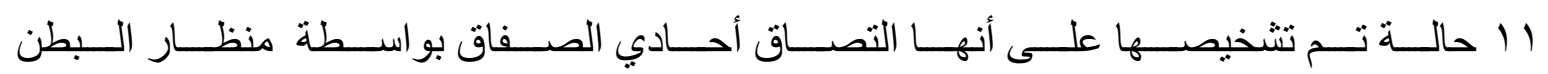

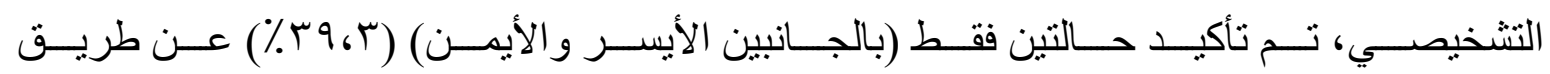

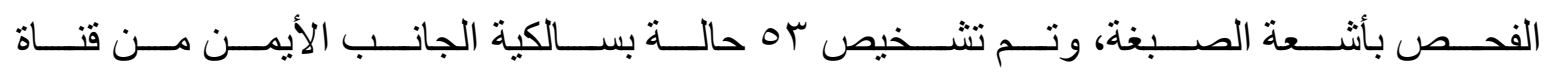

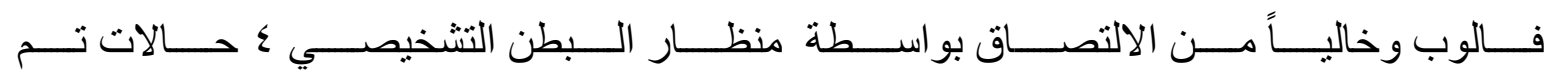

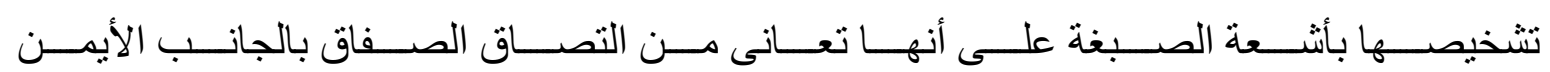

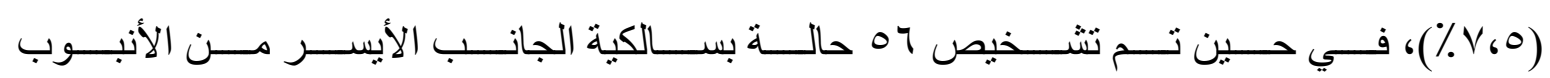
وخالي من الالتصاق بواسطة منظار البطن التشخيصي.

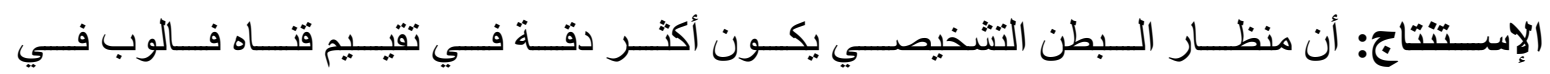
المرضى الذين يعانون من العقم أكثر من الأشعة بالصبغة. 